\title{
Research Paper: \\ Preserved Ovarian Function Following Toxicity With Doxorubicin in Rats: Protective Effect of Nasturtium Officinale Extract
}

\author{
Parastou Rad $^{1}$ (D), Fahimeh Safari ${ }^{2}$ (D), Jamshid Mohammadi ${ }^{3}$ (D), Hamdollah Delaviz ${ }^{4 *}$ (i)
}

1. Department of Nursing, School of Medicine, Yasuj University of Medical Sciences, Yasuj, Iran.

2. Department of Biology, Cellular and Molecular Research Center, Shiraz University, Shiraz, Iran.

3. Department of Physiology, School of Medicine, Yasuj University of Medical Sciences, Yasuj, Iran

4. Cellular and Molecular Research Center, School of Medicine, Yasuj University of Medical Sciences, Yasuj, Iran.

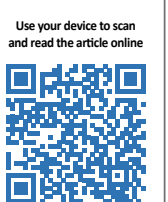

How to cite this paper Rad P, Safari F, Mohammadi J, Delaviz H. Preserved Ovarian Function Following Toxicity With Doxorubicin in Rats: Protective Effect of Nasturtium Officinale Extract. Iranian Journal of Toxicology. 2021; 15(1):57-64. http:// dx.doi.org/10.32598/ijt.15.1.747.1

http://dx.doi.org/10.32598/ijt.15.1.747.1

(c) (i) (s)

Article info:

Received: 03 Sep 2020

Accepted: 06 Dec 2020

Online Published: 01 Jan 2021

* Corresponding author:

Hamdollah Delaviz, PhD.

Address: Cellular and Molecular

Research Center, School of Medicine,

Yasuj University of Medical Sciences,

Yasuj, Iran

E-mail:delavizhamdi83@gmail.com

\section{ABSTRACT}

Background: Chemotherapy agents can cause ovarian dysfunction and eventually lead to infertility. This study investigated the effect of nasturtium officinale extract on the ovarian function following the toxicity induced by doxorubicin in female rats.

Methods: Forty eight female Wistar rats $(180-210 \mathrm{~g})$ were randomly divided in six groups as follows: Group I, normal rats receiving $1 \mathrm{ml}$ normal saline; Group II and III receiving 25 and $75 \mathrm{mg} / \mathrm{kg}$ of the extract daily by gavage for 21 days. Groups IV, V and VI receiving $10 \mathrm{mg} /$ $\mathrm{kg}$ doxorubicin intraperitoneally on the first day. In addition, Group IV and V received 25 and $75 \mathrm{mg} / \mathrm{kg}$ of the extract, respectively. The serum levels of estrogen, progesterone, Follicle Stimulating Hormone (FSH), Luteinizing Hormone ( $\mathrm{LH}$ ) and ovarian Malondialdehyde (MDA) were determined after 21 days of treatment. The mean numbers of various graafian follicles and corpus lutea were recorded after treatment.

Results: The mean serum FSH level in Group VI $(0.11 \pm 0.01)$ significantly reduced compared to those in Groups II $(0.21 \pm 0.05)$ and III $(0.23 \pm 0.01),(\mathrm{P}<0.05)$. The mean serum LH and estrogen levels in Group VI $(0.16 \pm 0.08)$ reduced insignificantly compared to those in the controls $(0.21 \pm 0.02)$, and in Groups II $(0.23 \pm 0.03)$ and III $(0.22 \pm 0.09)$. A significant reduction in the number of primary, secondary and graafian follicles were observed in Group VI compared to the control group $(\mathrm{P}<0.05)$. The serum MDA level significantly declined in Group $\mathrm{V}$ compared to that in Group VI $(\mathrm{P}<0.05)$.

Conclusion: The nasturtium officinale extract attenuated the toxic effect of doxorubicin on the rat ovaries and protected the cell division in the follicles and the oocytes maturation.

Keywords: Doxorubicin, Drug interactions, Nasturtium officinale, Ovaries, Rats

\section{Introduction}

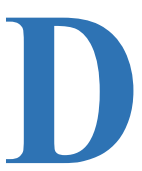

oxorubicin is an antitumor drug used for the treatment of different cancers, such as breast cancer, solid tumor and gastrointestinal cancer [1]. As a chemotherapy drug, doxorubicin has several complica- tions including, bone marrow suppression, ovarian insufficiency and heart damage [1,2]. Unfortunately, the long-term use of doxorubicin causes unwanted toxic effects, such as leukemia and induced ovarian cortical fibrosis and germ cell damage $[3,4]$. 
The ovarian histology after treatment with doxorubicin showed fibrosis in the ovarian cortex and induced apoptosis in the arterial endothelium [5]. The stromal changes and reduction in the follicular reserves cause ovarian failure to produce estrogen and progesterone [6]. Doxorubicin slows down the proliferation of cancer cells by inhibition of topoisomerase activity, causing tumor cell death [7]. At high doses, doxorubicin increases reactive oxidation, causing heart complications, apoptosis of follicular cells and ovarian parenchymal changes [8]. Specifically, this chemotherapeutic agent induces damage to the follicular cells at varying growth stages of oogenesis. The primordial follicles are especially sensitive to toxic drugs and inhibitors of topoisomerase activity, such as doxorubicin [9].

The mechanisms by which chemotherapy induces ovarian toxicity are inadequately studied in women [10]. It has been reported that a variety of chemotherapeutic drugs, such as bleomycin, doxorubicin and valrubicin, induce DNA damage by binding to the DNA and prevent the transcription process [11]. Some antioxidant substances can inhibit DNA damage in the follicular cells when exposed to toxic drugs before apoptosis. A previous study has indicated that polyphenols in foods or spices, such as curcumin, gallate, epicatechin, and resveratrol, have potent anti-tumor properties and are protective to the health of the reproductive system in cancer patients $[12,13]$. Antioxidant agents effectively inhibit the carcinogenic properties of drugs and protect cells from the damaging effect of Reactive Oxygen Species (ROS). A disproportional rise in the intracellular ROS induces apoptosis and inhibits cancer cell cycle [12, 14]. This can also be achieved with chemotherapy, depletion of cells from antioxidant proteins or generation of ROS by immune cells $[13,15]$.

Nasturtium officinale (N. officinale), also known as watercress, is an aquatic plant belonging to Brassicaceae family and is rich in vitamins and minerals. They grow rapidly in fresh water and are extensively used as a leafy vegetable food by humans. The plant has important role in the water ecosystems and creates favorable environment for many amphibian organisms, such as small fish [16]. The leaves of this plant are traditionally used as medicine in some parts of Iran in the treatment of kidney stones, diabetes and high blood pressure. The presence of flavonoids, phytochemicals, antioxidant phenolic and $\beta$-carotene has been confirmed in the extract of N. officinale [16]. As a healthy diet, the flowers of this plant contain useful elements, such as magnesium, potassium and zinc. These elements have an important health role in growth, cell division and the immune system function [17].
However, when chemotherapeutic agents are used in the treatment of cancers of breast, ovaries and uterine, the treatment is associated with detrimental effects, leading to infertility and declined sex hormone level [18]. Therefore, the aim of this study was to investigate the effects of hydroalcoholic extract of $\mathrm{N}$. officinale on the ovarian function in rats, and the status of ovarian lipid peroxidation following toxicity induced by doxorubicin. We have obtained promising results about ovarian hormone production and follicular development which will be discussed in this article.

\section{Materials and Methods}

Collection and Extraction of Plant Material: The leaves and aerial parts of the N. officinale were collected from the spring waters around the mount Dena in Fars Province, south west of Iran in May 2018. The plant samples were authenticated by Dr. A. Jafari at the Department of Botany, Yasuj University (Yasuj, Iran) and a voucher was issued (No.MPRC-YUMS-13). The plant samples were washed, dried in shade at room temperature and shredded finely in an electric grinder (\#3000, East Asan Toss, Tehran, Iran). A $500 \mathrm{~g}$ sample of N. officinale powder was dissolved in $70 \%$ ethyl alcohol in a percolator (Bayamad Technology Co., Tehran, Iran) and kept 72 hours at room temperature $\left(24 \pm 2^{\circ}\right.$ C). The solution was then filtered twice, using of a porous cloth and concentrated on a rotatory lyophilizer (Heidolph; Schwabach, Germany) at $50^{\circ} \mathrm{C}$ and under vacuum.

The extract: For dry powder preparation, the material was incubated for three days in the oven at $39^{\circ} \mathrm{C}$, and stored in a freezer (Pars-Iran Co., Tehran, Iran) at $-20^{\circ} \mathrm{C}$. Two extract solutions were prepared ( 25 and $75 \mathrm{mg} / \mathrm{ml}$ ). The extract powder was weighed accurately to the fourth decimal on an electronic scale (A \& D-HR 300, Japan), then dissolved in distill water and were given to rats by gavage.

Doxorubicin: For the preparation of doxorubicin, a 50mg vial (Sigma-Aldrich, Germany) was diluted in normal saline and kept in the freezer at $-4^{\circ} \mathrm{C}$. This was injected intraperitoneally at $10 \mathrm{Mg} / \mathrm{kg}$ body weight based the previously reported procedure [19].

Animals: The animal sample size was determined based on a previous study [20]. Forty eight adult female Wistar rats, weighing 180-210g were purchased from the animal house of Shiraz University of medical sciences. They were divided randomly into six equals groups of 8 animals each. The experiments were carried out based on Helsinki Declaration Guidelines, which are observed by both Shiraz and Yasuj Universities of Medical Sciences. All experiments with animals were ensured to minimize pain and suffering of the rats. 
Animal grouping: Group I (normal controls) received a single $1 \mathrm{ml}$ normal saline by gavage daily for 21 days, Group II and III were treated with one daily dose of 25 and $75 \mathrm{Mg} / \mathrm{kg}$ of the extract, respectively, for 21 days, based on a previous study [21]. Groups IV and V received one intraperitoneal injection of $10 \mathrm{mg} / \mathrm{kg}$ doxorubicin on the first day, followed by a 25 or $75 \mathrm{Mg} / \mathrm{kg}$ of the extract, respectively, by gavage for the next 21 days. Group VI was treated with a single dose of $10 \mathrm{mg} / \mathrm{kg}$ of doxorubicin on the first day of the experiment, as previously described [19]. Vaginal smears were taken to identify the estrous stage on a microscope (Olympus BX51, Japan). Based on the type of cells present on the vaginal smears, the estrous cycles were identified in the rats.

Serum hormones measurement: At the completion of the 21-day experiments, the rats from each group were anesthetized with a combination of ketamine $(80 \mathrm{mg} / \mathrm{kg})$ and xylazine $(10 \mathrm{mg} / \mathrm{kg})$. The blood samples were taken by heart puncture and stored at room temperature for 20 minutes to prepare serum. The samples were centrifuged at $3000 \mathrm{rpm}$ for 20 minutes at $4^{\circ} \mathrm{C}$ (Hettich EBA 200 centrifuge, Japan), and the serum levels of estrogen, progesterone, Follicle Stimulating Hormone (FSH) and Luteinizing Hormone (LH) were assayed, using ELISA kits (Cusabio Biotech, Wuhan, China). Blood samples and standards were measured in duplicate and the mean values for each sample were used in the analysis.

Histomorphometry study: After the animals were euthanized, the right ovary from each rat was dissected free of the adjacent mesentery and fat tissue. They were weighed, washed, dehydrated and embedded in paraffin wax blocks. The ovaries were sectioned into $5 \mu \mathrm{m}$ pieces on a rotary microtome (DS 4055; Deed Sabz Co., Tehran, Iran). Every second sections were mounted on gelatin-coated glass slides, stained with hematoxylin and eosin, dehydrated and covered with glass slip. The histological changes in the ovaries were examined microscopically (Olympus Ax70, Japan), and the numbers of primary, secondary, graafian follicles and corpus lutea were counted and recorded.

Malonaldehyde levels: The concentration of the ovarian lipid peroxidation was determined for the rats in each group based on a previously described method [22]. The left ovary from each rat was removed, separated from adjacent tissues and washed in normal saline. The mean concentration of Malondialdehyde (MDA) was determined for each group, using thiobarbituric acid test as previously described [23]. The ovarian tissue samples were homogenized (IKA, Werke, Germany) in $1.5 \% \mathrm{KCl}$ for 3 minutes. Then, $1 \mathrm{ml}$ thiobarbituric acid
$(6 \%)$ and $3 \mathrm{ml}$ phosphoric acid (1\%) were added to the homogenate, and the mixture was incubated at $98^{\circ} \mathrm{C}$ for an hour. After cooling, $4.5 \mathrm{ml}$ of n-butanol was added to the mixture, vortexed for one minute and centrifuged at $3000 \mathrm{rpm}$ for 25 minutes. The absorbance of the supernatant was measured at $532 \mathrm{~nm}$, on a spectrophotometer. The standard curve was drawn, using 1,1,3,3-tetramethoxypropane and the MDA concentration was expressed as nmol/g of the tissue.

Data analyses: The data analyses were performed using one-way ANOVA followed by Tukey's post-hoc test (Prism 5; Graphpad Software Inc., San Diego, CA). All data are expressed as the Mean \pm SD. A $\mathrm{P}<0.05$ was considered as being statistically significant.

\section{Results}

Serum Levels of Progesterone, Estrogen, FSH and LH: The results demonstrated that the mean progesterone level in Group VI rats that received doxorubicin was significantly reduced compared to those for Groups II and III that received 25 and $75 \mathrm{mg} / \mathrm{kg}$, respectively, of the extract $(\mathrm{P}<0.05)$ (Table 1). The mean FSH level in Groups $\mathrm{IV}$ and $\mathrm{V}$ decreased insignificantly compared to those in Groups II and III that received the extract only ( $\mathrm{P}>0.05)$. As shown in Table 1, the means of LH and estrogen levels in Group VI were reduced insignificantly compared to those in Groups II and III, and the controls. The mean LH and estrogen levels in Groups IV and V were lower than those in Groups II and III, and the controls insignificantly.

Alterations in follicles: As shown in Table 2, a significant reduction of the primary, secondary and graafian follicles were recorded in Group VI compared to those in the controls $(\mathrm{P}<0.05)$. No significant changes were detected in these follicles in Groups IV and V that received both the extract and doxorubicin compared to Groups II and III, and the controls. The number of corpus lutea in both the controls and those treated with the extract increased significantly compared to Group VI that received doxorubicin alone (Table 2). The mean number of Graafian follicles increased significantly in other groups compared to those in Group VI that received doxorubicin only (Figure 1). Although the mean number of primary, secondary and Graafian follicles increased in Group V compared with Group IV that received doxorubicin plus 75 or $25 \mathrm{mg} / \mathrm{kg}$ of the extract, the differences were not significant (Figure 1).

Histomorphological changes: The result demonstrated that doxorubicin reduced the follicular and theca cells in Group VI compared to the controls and Group V 
Table 1. Mean serum levels of FSH, LH, Estrogen and Progesterone in rats after 21 days of treatment with the N. officinale extract

\begin{tabular}{ccccc}
\hline \multirow{2}{*}{ Group } & \multicolumn{3}{c}{ Mean \pm SD } \\
\cline { 2 - 5 } & FSH mIU/mL & LH mlU/mL & Estrogen pg/ml & Progesterone pg/ml \\
\hline Control (I) & $0.18 \pm 0.08$ & $0.21 \pm 0.02$ & $482.23 \pm 12.23$ & $10.83 \pm 1.12$ \\
\hline NOE 25mg/kg (II) & $0.21 \pm 0.05^{*}$ & $0 / 23 \pm 0.03$ & $51.17 \pm 5.01$ & $11.91 \pm 1.32$ \\
\hline NOE 75mg/kg (III) & $0.23 \pm 0.01^{*}$ & $0.22 \pm 0.09$ & $54.91 \pm 1.01$ & $13.51 \pm 1.13$ \\
\hline NOE 25mg/kg+ Doxorubicin IV & $0.13 \pm 0.07$ & $0.17 \pm 0.06$ & $42.41 \pm 2.83$ & $5.51 \pm 1.94$ \\
\hline NOE 75mg/kg+ Doxorubicin (V) & $0.14 \pm 0.02$ & $0.19 \pm 0.02$ & $46.63 \pm 6.12$ & $7.63 \pm 1.42^{*}$ \\
\hline Doxorubicin (VI) & $0.11 \pm 0.01^{* *}$ & $0.16 \pm 0.08$ & $40.32 \pm 8.11$ & $4.42 \pm 1.53^{* * *}$ \\
\hline
\end{tabular}

${ }^{*}$ Compared to the group VI $(\mathrm{P}<0.05) ;{ }^{* *}$ Compared to the group I $(\mathrm{P}<0.01) ;{ }^{* * *}$ Compared to groups 1-3 $(\mathrm{P}<0.001) ;{ }^{*}$ Compared to group $4(\mathrm{P}<0.01)$.

Table 2. Mean number of follicles \& corpus luteum in rat groups after 21 days of treatment, N. officinale extract

\begin{tabular}{ccccc}
\hline \multirow{2}{*}{ Group } & \multicolumn{4}{c}{ Mean \pm SD } \\
\cline { 2 - 5 } & Primary Follicle & Secondary Follicle & Graafian Follicle & Corpus Luteum \\
\hline Control (I) & $6.52 \pm 3.21$ & $3.53 \pm 1.12$ & $3.63 \pm 0.03$ & $3.01 \pm 0.41$ \\
\hline NOE 25mg/kg (II) & $6.42 \pm 2.20$ & $3.41 \pm 0.20$ & $3.12 \pm 0.11$ & $3.52 \pm 1.32$ \\
\hline NOE 75mg/kg (III) & $7.14 \pm 2.13$ & $3.11 \pm 0.05$ & $3.42 \pm 0.09$ & $3.13 \pm 0.63$ \\
\hline NOE 25mg/kg+ Doxorubicin (IV) & $4.32 \pm 1.31$ & $2.13 \pm 0.13$ & $3.91 \pm 0.08^{* *}$ & $2.51 \pm 0.31^{* *}$ \\
\hline NOE 75mg/kg+ Doxorubicin (V) & $5.41 \pm 1.43$ & $2.92 \pm 0.02$ & $3.20 \pm 0.04^{* *}$ & $2.91 \pm 1.60^{* *}$ \\
\hline Doxorubicin (VI) & $3.01 \pm 1.11^{*}$ & $1.72 \pm 0.03^{*}$ & $1.04 \pm 0.02^{*}$ & $0.05 \pm 0.03^{*}$ \\
\hline
\end{tabular}

*Compared to groups1-3 $(\mathrm{P}<0.01)$; ${ }^{* *}$ Compared to group VI $(\mathrm{P}<0.05)$.

Table 3. The body and ovarian weights versus Malondialdehyde, N. officinale extract

\begin{tabular}{cccc}
\hline \multirow{2}{*}{ Group } & \multicolumn{3}{c}{ Mean \pm SD } \\
\cline { 2 - 4 } & Animals Weight (g) & Ovarian Weight (g) & Malondialdehyde (nmol/g) \\
\hline Control (I) & $267.71 \pm 21.32^{* * *}$ & $0.19 \pm 0.02$ & $98.36 \pm 11.21$ \\
\hline NOE 25mg/kg (II) & $240.62 \pm 21.51$ & $0.11 \pm 0.03$ & $93.49 \pm 10.33$ \\
\hline NOE 75mg/kg (III) & $211.91 \pm 18.53$ & $0.09 \pm 0.01$ & $92.17 \pm 10.51$ \\
\hline NOE 25mg/kg+ Doxorubicin (IV) & $224.21 \pm 17.23$ & $0.07 \pm 0.02$ & $117.81 \pm 13.06$ \\
\hline NOE 75mg/kg+ Doxorubicin (V) & $211.80 \pm 12.52$ & $0.09 \pm 0.03^{* *}$ & $127.65 \pm 15.32^{*}$ \\
\hline Doxorubicin (VI) & $208.82 \pm 22.62$ & $0.05 \pm 0.03^{*}$ & $178.48 \pm 17.43 ¥$ \\
\hline
\end{tabular}

*Compared to group 1-3 $(\mathrm{P}<0.01)$; ${ }^{* *}$ Compared to group $4(\mathrm{P}<0.05) ;{ }^{* * *}$ Compared to groups 3-6 $(\mathrm{P}<0.05)$;

${ }^{¥}$ Compared to the group $\mathrm{V}(\mathrm{P}<0.05)$ Means \pm SD.

that received doxorubicin plus the extract (Figure 2). The number of granulosa cells and the thickness of the theca decreased in the Graafian follicles of the rats treated with doxorubicin alone (Figure 2C). The light microscopic evaluation of the ovarian tissue samples demonstrated that the internal and external theca and granulosa cells appeared normal in the control group (Figure 2A). The consumption of $75 \mathrm{mg} / \mathrm{kg}$ of the extract altered the histological appearance toward normalcy in Group V that received both doxorubicin and the extract (Figure 2B).

The mean ovarian MDA: As shown in Table 3, the mean serum MDA level in Group VI that received doxorubicin increased significantly compared to other groups 

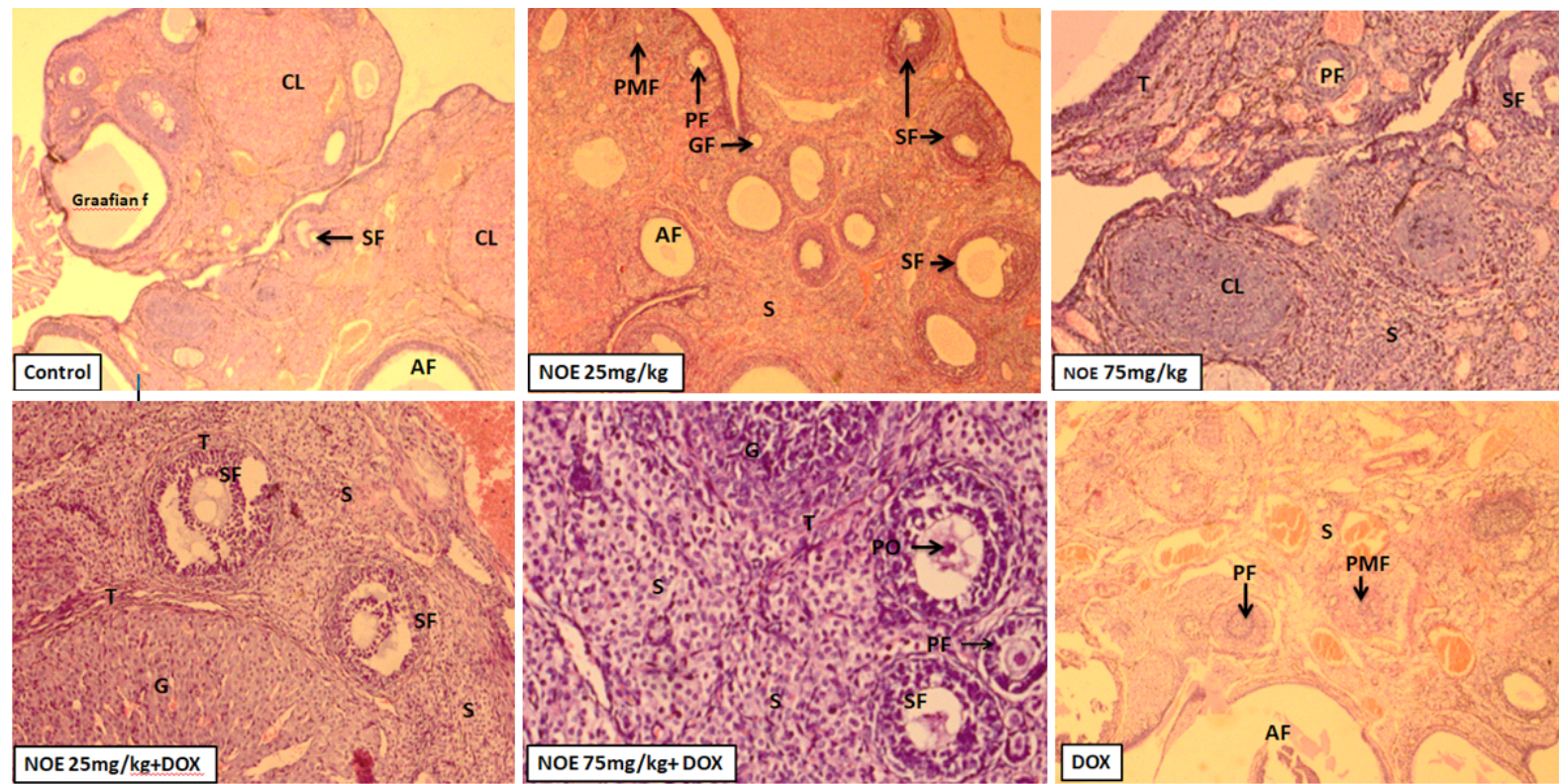

Figure 1. Light microscopic sections from the ovary tissue samples of rats after 21 days of treatment

Normal ovarian tissue found in the control healthy rats (I). PO: Primary Oocyte; GF: Growing Follicle; CL: Corpus Luteum; SF: Secondary Follicle; PMF: Primordial Follicle; AF: Antrum Follicle; G: Granulosa cells; S: Stroma; T: Theca were seen in different groups. All images were stained with H\&E staining, $5 \mu \mathrm{m}$ thick section, Scale bar, $50 \mu \mathrm{m}$.

$(\mathrm{P}<0.01)$. The consumption of $75 \mathrm{mg} / \mathrm{kg}$ of the extract in Group V decreased the mean serum level of MDA significantly compared to those in Group VI $(\mathrm{P}<0.01)$. Although the mean serum level of MDA in Group IV decreased compared to that in Group V, the difference was not significant $(\mathrm{P}>0.05)$.

Body and ovarian weight: After 21days of treatment, the results indicated that the rats' body weight in the control group increased significantly compared to those in Groups IV and V (Table 3). The mean ovarian weight in Group VI decreased significantly compared to those in the controls and Group V $(\mathrm{P}<0.05)$. Also, the consump- tion of $75 \mathrm{mg} / \mathrm{kg}$ of the extract in the Group V led to a significant increase in the mean ovarian weight compared to that in Group IV $(\mathrm{P}<0.05)$.

\section{Discussion}

Our results demonstrated that doxorubicin caused a significant reduction in the serum FSH level in rats that received doxorubicin alone. FSH is one of the essential hormones that stimulate the growth of follicles, pubertal maturation and the function of women's ovaries. Further the mean serum progesterone level decreased significantly in Group VI compare to those in other groups.
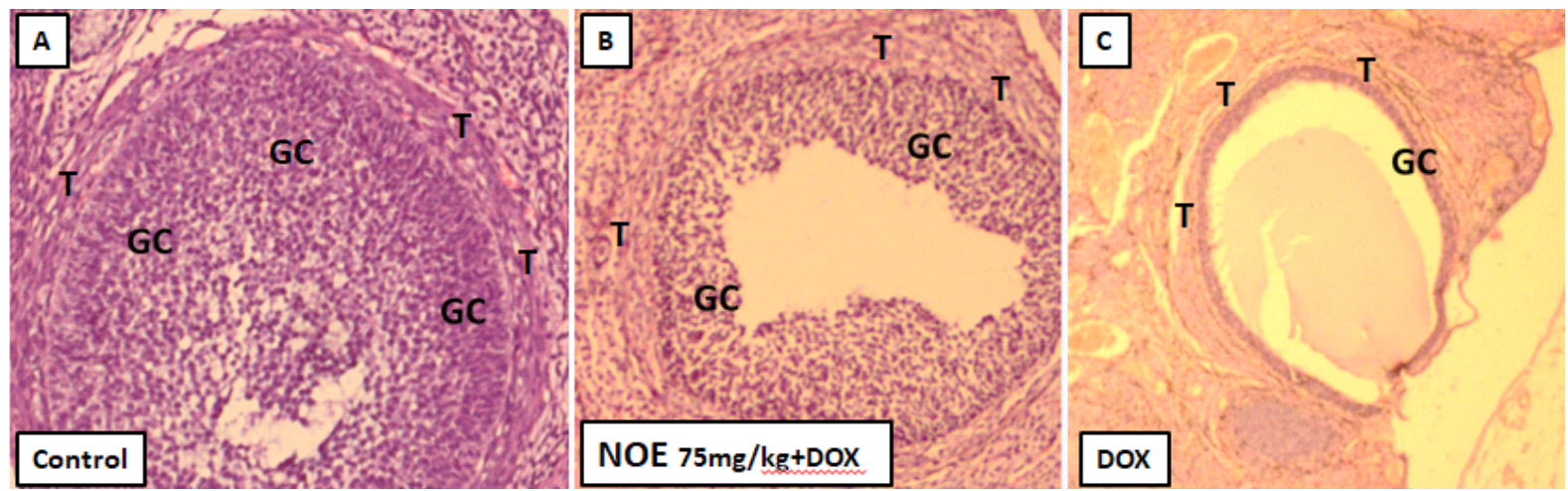

Figure 2. Light microscopic sections from ovaries

GC: Granulosa Cells; T: Theca were seen in different groups; All images were stained with H\&E staining; $5 \mu \mathrm{m}$ thick section; Scale bar; $50 \mu \mathrm{m}$. 
Previous studies have shown that a single injection of doxorubicin $(10 \mathrm{mg} / \mathrm{kg})$ in mice has toxic effects to the ovaries and reduces the number of primary follicles compared with controls $[9,19,24]$.

Consistently, the present study demonstrated the mean number of primary, secondary and Graafian follicles decreased significantly in rats that received doxorubicin only compared to the controls and those in groups that received the extract only. Chemical compounds, such as doxorubicin and cyclophosphamide that generate toxic metabolites induce lipid peroxidation and cause apoptotic changes in antral follicles [20, 25]. In our study, the serum MDA level increased and the number of primary follicles decreased in the rats that received doxorubicin alone. The findings are consistent with those reported by a previous, showing that primary follicles were very sensitive to free radicals, and their cells underwent apoptosis [26].

Another study has shown that a single dose of doxorubicin in mice $(10 \mathrm{mg} / \mathrm{kg})$ had toxic effects on the ovaries and reduced the number of primary follicles compared to those in the control mice [19]. Consistently, we demonstrated that the mean numbers of primary, secondary and Graafian follicles decreased significantly in Group VI (doxorubicin only) compared to those in the controls and the groups that received the extract alone. Being an antineoplastic agent with alkylating effects, doxorubicin is known to be toxic to ovaries, causing follicular cell damage, apoptosis, and inhibiting cellular proliferation [20].

Doxorubicin has been used successfully in the treatment of malignant tumors particularly in childhood cancer [27]. The mechanisms by which doxorubicin induces renal, ovarian, hepatic and cardiovascular toxicity are not well understood [28]. It has been hypothesized that doxorubicin, as an iron chelator, promotes lipid peroxidation and oxygen consumption [29]. Another study has demonstrated that even a low dose of doxorubicin $(3 \mathrm{mg} /$ $\mathrm{kg}$ ) in mouse has adverse effects on the follicular development and hormone production [30]. The present study examined the adverse effects of doxorubicin on the follicle numbers and ovarian weight.

These findings were supported by another study that demonstrated the combination of doxorubicin and cisplatin significantly decreased the follicular cell numbers and the growth in mice [31]. Antioxidant compounds and chelators can reduce the toxic effects of anticancer agents [32]. The extract of $\mathrm{N}$. officinale with its high contents of antioxidant, beta carotene and lutein can not only protect ovaries but also other organs from oxygen free radicals [33].
A well documented study has demonstrated that the daily consumption of $\mathrm{N}$. officinale extract prevents lung cancer in smokers [34]. It has been shown that the extract contains isothiocyanate with a known protective effect against cancer cells [35]. More recently, a clinical study has demonstrated that the crude extract of $\mathrm{N}$. officinale has anti-metastatic property and can inhibit the cellular division in human colon cancer cells [36].

Limitation of the Study: A major limitation of this study was performing the gavage procedure because we encountered resistance from the rats in the first week of the study and there was a possibility of causing damage to their gastrointestinal tracts.

Recommendation for Future Research: Future studies are warranted to identify the specific bioactive compounds or molecules in N. officinale with the potential to develop protective agents against the side effects of doxorubicin and other chemotherapy drugs for specific clinical trials.

\section{Conclusions}

This study indicated that the administration of N. officinale extract had protective effects on rat ovaries against doxorubicin-induced toxicity. The extract improved the ovarian function with respect to the production of progesterone and estrogen hormones, and improved the follicular and granulosa cells divisions. Our results confirmed that the extract also had protective effects against the lipid peroxidation caused by doxorubicin toxicity as shown by the reduced ovarian MDA level. The findings suggest that the protective effects are likely related to the antioxidant and anticancer properties of the extract. Further studies are required to assess the therapeutic effects of $\mathrm{N}$. officinale on cell proliferation and growth in other organs, especially when the cells are exposed to carcinogenic substances.

\section{Ethical Considerations}

\section{Compliance with ethical guidelines}

This study were carried out in accordance with established institutional Guidelines for the Care of Laboratory Animals (GCLA) and approved by the Ethics Committee of Yasuj University of Medical Sciences.

\section{Funding}

This research study was financially supported by a grant from Yasuj University of Medical Sciences. 


\section{Author's contributions}

Data collection, preparing the manuscript: Parastou, Jamshid Mohmmadi; Implementation, resources: Fahimeh Safari; Study design: Fahimeh Safari, Hamdollah Delaviz; Supervision, data analyses: Hamdollah Delaviz; Reading the contents and approving the final draft of the manuscript: All authors.

\section{Conflict of interest}

The authors declared no conflict of interests.

\section{Acknowledgements}

The authors acknowledge the professors and staffs of Yasuj University of Medical Sciences for their support and providing the laboratories and equipment toward the conduction of this study.

\section{References}

[1] Chytil P, Šírová M, Kudláčová J, Říhová B, Ulbrich K, Etrych T. Bloodstream stability predetermines the antitumor efficacy of micellar polymer-doxorubicin drug conjugates with pH-triggered drug release. Mol Pharm. 2018; 15(9):3654-63. [DOI:10.1021/acs.molpharmaceut.8b00156] [PMID]

[2] Lishner M, Elis A, Ravid M. Late doxorubicin cardiotoxicity. Anticancer Drugs. 1992; 3(4):367-9. [DOI:10.1097/00001813199208000-00008] [PMID]

[3] Ansari L, Shiehzadeh F, Taherzadeh Z, Nikoofal-Sahlabadi S, Momtazi-Borojeni AA, Sahebkar A, et al. The most prevalent side effects of pegylated liposomal doxorubicin monotherapy in women with metastatic breast cancer: A systematic review of clinical trials. Cancer Gene Ther. 2017; 24(5):189-93. [DOI:10.1038/cgt.2017.9] [PMID]

[4] Pendlebury A, DeBernardo R, Rose PG. Long-term use of pegylated liposomal doxorubicin to a cumulative dose of 4600 $\mathrm{mg} / \mathrm{m} 2$ in recurrent ovarian cancer. Anticancer Drugs. 2017; 28(7):815-7. [DOI:10.1097/CAD.0000000000000521] [PMID]

[5] Wang Y, Liu M, Johnson SB, Yuan G, Arriba A, Zubizarreta $\mathrm{ME}$, et al. Doxorubicin obliterates mouse ovarian reserve through both primordial follicle atresia and overactivation. Toxicol Appl Pharmacol. 2019; 381:114714. [DOI:10.1016/j. taap.2019.114714] [PMID] [PMCID]

[6] Wang Y, Liu M, Zhang J, Liu Y, Kopp M, Zheng W, et al. Multidrug resistance protein 1 deficiency promotes doxorubicin-induced ovarian toxicity in female mice. Toxicol Sci. 2018; 163(1):279-92. [DOI:10.1093/toxsci/kfy038] [PMID] [PMCID]

[7] Meredith AM, Dass CR. Increasing role of the cancer chemotherapeutic doxorubicin in cellular metabolism. J Pharm Pharmacol. 2016; 68(6):729-41. [DOI:10.1111/jphp.12539] [PMID]
[8] Formelli F, Carsana R, Pollini C. Pharmacokinetics of 4'-deoxy-4'-iodo-doxorubicin in plasma and tissues of tumorbearing mice compared with doxorubicin. Cancer Res. 1987; 47(20):5401-6.

[9] Zhang T, He WH, Feng LL, Huang HG. Effect of doxorubicin-induced ovarian toxicity on mouse ovarian granulosa cells. Regul Toxicol Pharmacol. 2017; 86:1-10. [DOI:10.1016/j. yrtph.2017.02.012]

[10] Ma Y, Chapman J, Levine M, Polireddy K, Drisko J, Chen Q. High-dose parenteral ascorbate enhanced chemosensitivity of ovarian cancer and reduced toxicity of chemotherapy. Sci Transl Med. 2014; 6(222):222-8. [DOI:10.1126/scitranslmed.3007154] [PMID]

[11] Hay AE, Meyer RM. Balancing risks and benefits of therapy for patients with favorable-risk limited-stage Hodgkin lymphoma: the role of doxorubicin, bleomycin, vinblastine, and dacarbazine chemotherapy alone. Hematol Oncol Clin North Am. 2014; 28(1):49-63. [DOI:10.1016/j.hoc.2013.10.001] [PMID] [PMCID]

[12] LiouGY,StorzP.Reactiveoxygenspeciesincancer.FreeRadic Res. 2010; 44(5):479-96. [DOI:10.3109/10715761003667554] [PMID] [PMCID]

[13] Carvalho LF, Silva AMF, Carvalho AA. The use of antioxidant agents for chemotherapy-induced peripheral neuropathy treatment in animal models. Clin Exp Pharmacol Physiol. 2017; 44(10):971-9. [DOI:10.1111/1440-1681.12803] [PMID]

[14] da Rocha PDS, Ferreira Campos J, Nunes-Souza V, do Carmo Vieira M, de Araújo Boleti AP, Rabelo LA, et al. Antioxidant and protective effects of schinus terebinthifolius raddi against doxorubicin-induced toxicity. Appl Biochem Biotechnol. 2018; 184(3):869-84. [DOI:10.1007/s12010-0172589-y] [PMID]

[15] Prasad S, Gupta SC, Tyagi AK. Reactive Oxygen Species (ROS) and cancer: Role of antioxidative nutraceuticals Cancer Lett. 2017; 387:95-105. [DOI:10.1016/j.canlet.2016.03.042] [PMID]

[16] Palaniswamy U, McAvoy R, Bible BB, Stuart JD. Ontogenic variations of ascorbic acid and phenethyl isothiocyanate concentrations in watercress (Nasturtium officinale R.Br.) leaves. J Agric Food Chem. 2003; 51(18):5504-9. [DOI:10.1021/ jf034268w] [PMID]

[17] Klimek-Szczykutowicz M, Szopa A, Ekiert H. Chemical composition, traditional and professional use in medicine, application in environmental protection, position in food and cosmetics industries, and biotechnological studies of $\mathrm{Na}-$ sturtium officinale (watercress) - A review. Fitoterapia. 2018; 129:283-92. [DOI:10.1016/j.fitote.2018.05.031] [PMID]

[18] Tao TJ, Visvanathan K, C Wolff AC. Long term side effects of adjuvant chemotherapy in patients with early breast cancer Breast. 2015; 24(2):S149-53. [DOI:10.1016/j.breast.2015.07.035] [PMID] [PMCID]

[19] Ben-Aharon I, Bar-Joseph H, Tzarfaty G, Kuchinsky L, Rizel S, Stemmer SM, et al. Doxorubicin-induced ovarian toxicity. Reprod Biol Endocrinol. 2010; 8:20-31. [DOI:10.1186/14777827-8-20] [PMID] [PMCID]

[20] Nishi K, Gunasekaran VP, Arunachalam J, Ganeshan M. Doxorubicin-induced female reproductive toxicity: An assessment of ovarian follicular apoptosis, cyclicity and reproductive tissue histology in Wistar rats. Drug Chem Toxicol. 
2018; 41(1):72-81. [DOI:10.1080/01480545.2017.1307851] [PMID]

[21] Akbari Bazm M, Khazaei M, Khazaei F, Naseri L. Nasturtium Officinale L. hydroalcoholic extract improved oxymetholone-induced oxidative injury in mouse testis and sperm parameters. Andrologia. 2019; 51(7):e13294. [DOI:10.1111/ and.13294] [PMID]

[22] Caglayan A, Katlan DC, Selçuk Tuncer Z, Yüce K, Sayel $\mathrm{HB}$, Salman MC, et al. Impaired antioxidant enzyme functions with increased lipid peroxidation in epithelial ovarian cancer. IUBMB Life. 2017; 69(10):802-13. [DOI:10.1002/ iub.1675] [PMID]

[23] Ghowsi M, Khazali H, Sisakhtnezhad S. The effect of resveratrol on oxidative stress in the liver and serum of a rat model of polycystic ovary syndrome: An experimental study. Int J Reprod Biomed. 2018; 16(3):149-58. [DOI:10.29252/ ijrm.16.3.149] [PMID] [PMCID]

[24] Aziz AUR, Yu X, Jiang Q, Zhao Y, Deng S, Qin K, et al. Doxorubicin-induced toxicity to 3D-cultured rat ovarian follicles on a microfluidic chip. Toxicol In Vitro. 2020; 62:104677. [DOI:10.1016/j.tiv.2019.104677] [PMID]

[25] Ting AY, Petroff BK. Tamoxifen decreases ovarian follicular loss from experimental toxicant DMBA and chemotherapy agents cyclophosphamide and doxorubicin in the rat. J Assist Reprod Genet. 2010; 27(11):591-7. [DOI:10.1007/s10815-0109463-y] [PMID] [PMCID]

[26] Chaudhary GR, Yadav PK, Yadav AK, Tiwari M, Gupta A, Sharma A, et al. Necroptosis in stressed ovary. J Biomed Sci. 2019; 26(1):11-7. [DOI:10.1186/s12929-019-0504-2] [PMID] [PMCID]

[27] Li M, Tang Z, Lin J, Zhang Y, Lv S, Song W, et al. Synergistic antitumor effects of doxorubicin-loaded carboxymethyl cellulose nanoparticle in combination with endostar for effective treatment of non-small-cell lung cancer. Adv Healthc Mater. 2014; 3(11):1877-88. [DOI:10.1002/adhm.201400108] [PMID]

[28] Kumral A, Giriş M, Soluk-Tekkeşin M, Türkoğlu Ü, Uysel M. Beneficial effects of carnosine and carnosine plus vitamin $\mathrm{E}$ treatments on doxorubicin-induced oxidative stress and cardiac, hepatic, and renal toxicity in rats. Hum Exp Toxicol. 2016; 35(6):635-43. [DOI:10.1177/0960327115597468] [PMID]

[29] Ichikawa Y, Ghanefar M, Bayeva M, Wu R, Khechaduri A, Naga Prasad SV, et al. Cardiotoxicity of doxorubicin is mediated through mitochondrial iron accumulation. J Clin Invest. 2014; 124(2):617-30. [DOI:10.1172/JCI72931] [PMID] [PMCID]

[30] Rudnick-Glick S, Corem-Salkmon E, Grinberg I, Margel S. Targeted drug delivery of near IR fluorescent doxorubicinconjugated poly (ethylene glycol) bisphosphonate nanoparticles for diagnosis and therapy of primary and metastatic bone cancer in a mouse model. J Nanobiotechnology. 2016; 14(1):807. [DOI:10.1186/s12951-015-0126-0] [PMID] [PMCID]

[31] Negrette-Guzman M. Combinations of the antioxidants sulforaphane or curcumin and the conventional antineoplastics cisplatin or doxorubicin as prospects for anticancer chemotherapy. Eur J Pharmacol. 2019; 859:172513. [DOI:10.1016/j. ejphar.2019.172513] [PMID]

[32] Sugimoto K, Tamayose K, Sasaki M, Hayashi K, Oshimi K. Low-dose doxorubicin-induced necrosis in Jurkat cells and its acceleration and conversion to apoptosis by antioxidants.
Br J Haematol. 2002; 118(1):229-38. [DOI:10.1046/j.13652141.2002.03577.x] [PMID]

[33] Klimek-Szczykutowicz M, Szopa A, Blicharska E, Dziurka M, Komsta L, Ekiert H. Bioaccumulation of selected macroand microelements and their impact on antioxidant properties and accumulation of glucosinolates and phenolic acids in in vitro cultures of Nasturtium officinale (watercress) microshoots. Food Chem. 2019; 300:125184. [DOI:10.1016/j.foodchem.2019.125184] [PMID]

[34] Hecht SS, Chung FL, Richie JP Jr, Akerkar SA, Skowronski L, Carmella SG. Effects of watercress consumption on metabolism of a tobacco-specific lung carcinogen in smokers. Cancer Epidemiol Biomarkers Prev. 1995; 4(8):877-84. [PMID]

[35] Freitas E, Aires A, Santos Rosa EA, José Saavedra M. Antibacterial activity and synergistic effect between watercress extracts, 2-phenylethyl isothiocyanate and antibiotics against 11 isolates of Escherichia coli from clinical and animal source. Lett Appl Microbiol. 2013; 57(4):266-73. [DOI:10.1111/ lam.12105] [PMID]

[36] Boyd LA, McCann MJ, Hashim Y, Bennett RN, Gill CIR, Rowland IR. Assessment of the anti-genotoxic, anti-proliferative, and anti-metastatic potential of crude watercress extract in human colon cancer cells. Nutr Cancer. 2006; 55(2):232-41. [DOI:10.1207/s15327914nc5502_15] [PMID] 